\title{
Original
}

\section{Pathological characteristics of Ccdc85c knockout rats: a rat model of genetic hydrocephalus}

\author{
Shizuka KONISHI ${ }^{1) *}$, Natsuki TANAKA ${ }^{1) *}$, Tomoji MASHIMO ${ }^{2)}$, Takashi YAMAMOTO ${ }^{3)}$, \\ Tetsushi SAKUMA ${ }^{3)}$, Takehito KANEKO ${ }^{4)}$, Miyuu TANAKA ${ }^{5)}$, Takeshi IZAWA ${ }^{1)}$, \\ Jyoji YAMATE $^{1)}$ and Mitsuru KUWAMURA ${ }^{1)}$ \\ 1) Laboratory of Veterinary Pathology, Graduate School of Agriculture and Biological Sciences, Osaka Prefecture University, \\ 1-58 Rinku Orai-Kita, Izumisano, Osaka 598-8531, Japan \\ 2) Institute of Experimental Animal Sciences, Graduate School of Medicine, Osaka University, 2-2 Yamadaoka, Suita, Osaka \\ 565-0871, Japan \\ 3) Molecular Genetics Laboratory, Graduate School of Integrated Sciences for Life, Hiroshima University, 1-3-1 Kagamiyama, \\ Higashi-Hiroshima, Hiroshima 739-8526, Japan \\ ${ }^{4)}$ Laboratory of Animal Reproduction and Development, Graduate School of Arts and Science, Iwate University, 4-3-5 Ueda, \\ Morioka, Iwate 020-8551, Japan \\ 5) Veterinary Medical Center, Osaka Prefecture University, 1-58 Rinku Orai-Kita, Izumisano, Osaka 598-8531, Japan
}

\begin{abstract}
Spontaneous hhy mice show hydrocephalus and subcortical heterotopia, and a mutation in the Ccdc85c gene has been identified. To contribute to the comparison of the role of Ccdc85c in different species, we established a $C c d c 85 \mathrm{c} \mathrm{KO}$ rat and investigated its pathological phenotypes. Ccdc85c KO rats were produced by genomic engineering using transcription activator-like effector nuclease (TALEN). The KO rats had an approximately 350-bp deletion in $C c d c 85 c$ and lacked CCDC85C protein expression. The KO rats showed non-obstructive hydrocephalus, subcortical heterotopia, and intracranial hemorrhage. The KO rats had many pathological characteristics similar to those in hhy mice. These results indicate that CCDC85C plays an important role in cerebral development in rats, and the function of CCDC85C in the cerebrum are similar in rats and mice.
\end{abstract}

Key words: $C c d c 85 c$, hydrocephalus, rat, subcortical heterotopia

\section{Introduction}

The hemorrhagic hydrocephalus (hhy) mouse is a spontaneous mutant with non-obstructive hydrocephalus, subcortical heterotopia and frequent brain hemorrhage [11]. A previous study [16] revealed that the hhy homozygous mouse has a mutation in the coiled-coil domain containing $85 \mathrm{c}(\mathrm{Ccdc} 85 \mathrm{c})$ gene and lacks protein expression of CCDC85C. The lack of CCDC85C expression in hhy homozygous mice results in abnormal migration of radial glia, the formation of subcortical heterotopia, and ependymal agenesis, leading eventually to hydrocephalus. Thus, the function of CCDC $85 \mathrm{C}$ is considered to be closely correlated with the maintenance of neural progenitor cells and neurogenesis in the central nervous system.

To definitively determine the function of $C c d c 85 c$, different species of animal model with the $C c d c 85 c$ gene knocked out ( $C c d c 85 c \mathrm{KO}$ ) would be useful. Many studies have reported that genetically engineered rats show a phenotype closer to humans than do mice, such as Adenomatous polyposis coli $(A p c) \mathrm{KO}$ rats and DNAPKcs $(P r k d c)$ KO rats $[2,15]$. Therefore, analyzing gene function in multiple species is important in clarifying the universal and species-specific functions of the causative gene.

(Received 18 January 2019 / Accepted 22 June 2019 / Published online in J-STAGE 23 July 2019)

Corresponding author: M. Kuwamura.e-mail: kuwamura@vet.osakafu-u.ac.jp

*These authors contributed equally to this work. 
In this study, we established $C c d c 85 c \mathrm{KO}$ rats and investigated their pathological phenotypes to compare them with those of hhy mice.

\section{Materials and Methods}

\section{Establishment of Ccdc85c knockout rats by TALEN}

Ccdc85c-deficient rats were established by genetic engineering using a highly active variant of transcription activator-like effector nuclease (TALEN), Platinum TALEN [20]. Platinum $C c d c 85 c$ TALEN, designed against rat $C c d c 85 c$ (NC_005105.4; NCBI), was constructed as previously described [20]. Briefly, DNAbinding repeats of TALEN were assembled using the two-step Golden Gate cloning method to bind the sequences 5'-TGGCGAAGCCCCCGGCG-3' (left) and 5'-TCCGACGCCGCCGCCGC-3' (right). The mRNA of left and right Platinum $C c d c 85 c$ TALEN was synthesized and injected into F344 rat zygotes. Platinum $C c d c 85 c$ TALEN-injected embryos were transferred into the oviducts of two pseudopregnant female rats. F0 rats were mated with control F344 rats. Then F1 male rats were mated with $\mathrm{F} 1$ female rats in each mutant lineage. On the basis of the clinical symptoms of the F2 rats, we chose lines to continue breeding. F2 rats and their offspring were used for genotyping, sequencing, histopathology and immunohistochemistry.

All rats were maintained under specific-pathogen-free conditions in a room with a controlled temperature and a 12-h light-dark cycle at the Animal Facility of Osaka Prefecture University. Food and water were provided $a d$ libitum. All rats were handled according to the Guidelines for Animal Experimentation of Osaka Prefecture University.

\section{Genotyping and sequencing}

Genotyping was performed by polymerase chain reaction (PCR) and the mutation site in $C c d c 85 c$ was identified by direct sequencing. Genomic DNA was extracted from tail or ear biopsies of rats using a KAPA Express Extract kit (Nippon Genetics, Tokyo, Japan). PCR was performed with Tks Gflex ${ }^{\mathrm{TM}}$ DNA Polymerase (Takara, Shiga, Japan). The primer sequences were 5'-CTGCCCAATCAGACCTGTG-3' (forward primer; AABR07065498; Ensembl) and 5'-AGCACCAGCTCTTTCAGCTC-3' (reverse primer; XM_001076332.2; NCBI). Since the reference genome of the rat is incorrect at the $C c d c 85 c$ locus, the sequence upstream of the start codon was obtained from AABR07065498, and the sequence after the start codon from XM_001076332.2. The PCR conditions were 1 cycle of $94^{\circ} \mathrm{C}$ for $1 \mathrm{~min}$ and 28 cycles of $98^{\circ} \mathrm{C}$ for $10 \mathrm{~s}$, $60^{\circ} \mathrm{C}$ for $15 \mathrm{~s}$, and $68^{\circ} \mathrm{C}$ for $30 \mathrm{~s}$. PCR products were analyzed by electrophoresis in 3\% agarose gels. The PCR products from each genomic DNA were directly sequenced. Sequence analysis was performed at Macrogen Japan Co. (Kyoto, Japan).

\section{Histopathology}

For histopathological analysis, homozygous ( $C c d c 85 c$ $\mathrm{KO})$ rats at four weeks of age $(4 \mathrm{~W})$, wild type (WT) at $4 \mathrm{~W}$ and $17 \mathrm{~W}$, and heterozygous (hetero) rats at $17 \mathrm{~W}$ were used. The rats were euthanized by isoflurane and the visceral organs removed and fixed in $10 \%$ neutral buffered formalin. The fixed tissues were processed by the routine method, embedded in paraffin wax, cut into $3-\mu \mathrm{m}$ sections and stained with hematoxylin and eosin (HE). In addition, the duodenum was removed to test for the expression of CCDC $85 \mathrm{C}$ protein immunohistochemically, embedded in TISSU MOUNT ${ }^{\circledR}$ (Chiba Medical, Saitama, Japan), rapidly frozen and stored at $-80^{\circ} \mathrm{C}$ to await the preparation of frozen sections as previously described [25]. In our previous study [25], we found that the expression of CCDC85C protein decreased with the development of the organs, whereas the intestine continued to express $\mathrm{CCDC} 85 \mathrm{C}$ protein even at postnatal day 60 (P60). Therefore, the expression of CCDC85C protein was evaluated in the duodenum.

\section{Production of rabbit polyclonal anti-rat CCDC85C antibody}

A segment of rat CCDC85C consisting of the C-terminal 187 residues (serine-119 to leucine-305) was expressed as a Glutathione S-transferase (GST)-fusion protein in Escherichia coli DH5a (XM_006240553.1, XP_006240615.1; NCBI). Using this protein, a rabbit polyclonal anti-rat $\mathrm{CCDC} 85 \mathrm{C}$ antibody was produced at Eve Bio-Science Co., Ltd. (Wakayama, Japan) as previously described [25].

\section{Immunohistochemistry}

For immunofluorescence staining, $10-\mu \mathrm{m}$ frozen sections of duodenum were cut on a cryostat and air-dried at room temperature for $1 \mathrm{~h}$. The tissue sections were fixed in Zamboni's solution $(0.21 \%$ picric acid, $2 \%$ paraformaldehyde) for $15 \mathrm{~min}$ at room temperature. The sections were then washed with $0.3 \%$ Triton X-100 in phosphate-buffered saline for $15 \mathrm{~min}$, treated with $10 \%$ normal goat serum (Sigma, St. Louis, MO, USA) for 30 min, and incubated with rabbit polyclonal antibody against rat $\mathrm{CCDC} 85 \mathrm{C}(1: 100,000)$ at $4^{\circ} \mathrm{C}$ overnight. The sections were incubated with Alexa488-labeled antirabbit IgG secondary antibody (1:1,000; Life Technologies, Carlsbad, CA, USA) for $45 \mathrm{~min}$ at room tempera- 
ture and coverslipped with mounting medium containing DAPI (Vector Laboratories, Burlingame, CA, USA). Signals were detected with a confocal imaging system (C1Si; Nikon, Tokyo, Japan).

\section{Results}

\section{Establishment of Ccdc85c knockout rats}

Nine F0 rats were obtained from two female rats. By direct sequencing, it was found that there were different mutations in each of the nine rats at the TALEN targeting site (data not shown). Three F0 rats died before mating; the cause of death in these rats could not be determined. In the observation of the general symptoms of the F2 rats, some rats derived from one rat line showed an enlarged head macroscopically. Rats of this lineage were maintained for use in further experiments.

In the PCR for genotyping, PCR products from unaffected rats showed two patterns: one band at $942 \mathrm{bp}$, and two bands at $942 \mathrm{bp}$ and around $600 \mathrm{bp}$ (Fig. 1A). Unaffected rats with one band were judged to be WT and unaffected rats with two bands were judged to be heterozygous. In contrast, the PCR products from rats with an enlarged head were around $600 \mathrm{bp}$, and were therefore about $350 \mathrm{bp}$ shorter than the 942-bp product from WT rats (Fig. 1A). Thus, affected rats were judged to be homozygous. Genotyping revealed that only homozygous rats exhibited macroscopic abnormality.

To test for CCDC85C protein expression, we performed immunofluorescence staining for CCDC85C in the duodenum using a polyclonal antibody against rat CCDC85C protein. Expression of CCDC85C at the api-
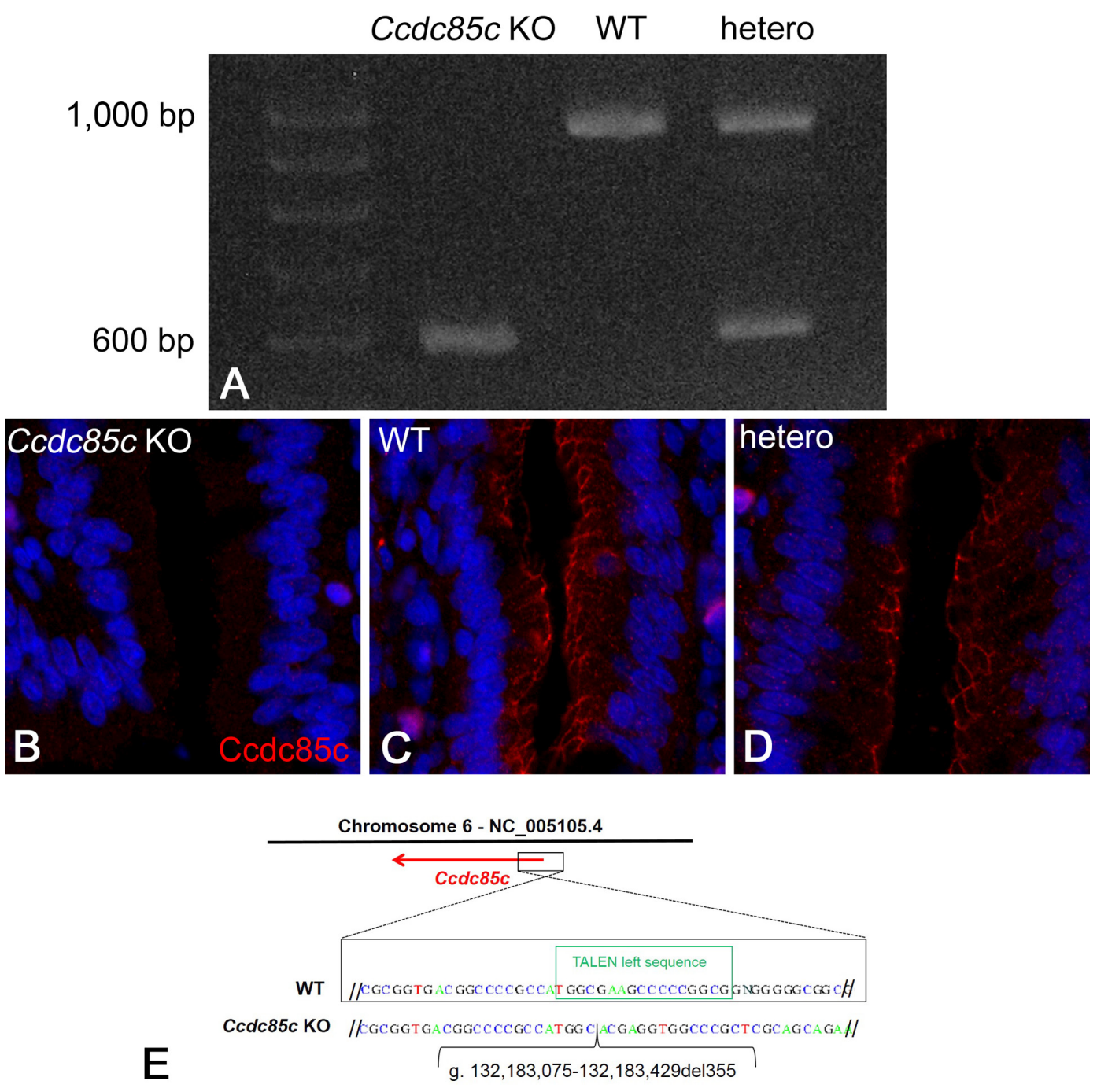

Fig. 1. PCR products from genomic DNA of $C c d c 85 c(\mathrm{~A}) . C c d c 85 c \mathrm{KO}$ rats have an approximately 350-bp deletion in $C c d c 85 c$. Immunofluorescence staining for CCDC85C protein in the duodenum (B-D). CCDC85C is expressed in the epithelial cells in wild type (WT) (C) and heterozygous (D) rats at 17W. CCDC85C expression was not observed in $C c d c 85 c \mathrm{KO}$ rats at four weeks of age (4W) (B). Scale bar, $25 \mu \mathrm{m}$. Sequences of the WT and $C c d c 85 c$ KO rat PCR products (E). A 355-bp genomic sequence encompassing exon 1 is deleted in $C c d c 85 c$ KO rats (g. 132,183,075-132,183,429del355; NCBI NC_005105.4). 
cal junctions of epithelial cells was detected in unaffected rats (Figs. 1C and D) but not in rats with an enlarged head (Fig. 1B). On the basis of PCR genotyping and immunofluorescence analysis, we consider the affected rats to be $C c d c 85 c \mathrm{KO}$ rats.

To identify the mutations of the TALEN targeting site in $C c d c 85 c$, PCR products from this site were directly subjected to DNA sequencing analysis. We found that a 355-bp genomic sequence encompassing exon 1 was deleted in affected rats (g. 132,183,075132,183,429del355; NCBI NC_005105.4) (Fig. 1E).

At the time of finalizing the data used in this paper, 73 rats had been obtained, among them $12 C c d c 85 c \mathrm{KO}$, $19 \mathrm{WT}$ and 42 hetero rats. Thus, the incidence of $C c d c 85 c$ KO rats was $16.4 \%$ and that of unaffected rats was $83.6 \%$. This segregation ratio is lower than the expected $1: 3$ ratio $\left(\chi^{2}=2.85 ; P=0.09\right)$. Prior to genotyping, young rats in poor condition were killed by the mother.

\section{Pathological phenotypes in $\mathrm{Ccdc} 85 \mathrm{c} \mathrm{KO}$ rats}

In $C c d c 85 c \mathrm{KO}$ rats, enlargement of the head was observed from around $\mathrm{P} 14$ and became prominent at $\mathrm{P} 30$ (Figs. 2A and B). $C c d c 85 c \mathrm{KO}$ rats showed difficulty in walking and most of them died around P30. Necropsy revealed that all $12 C c d c 85 c \mathrm{KO}$ rats had hydrocephalus (enlarged cranium with thin cranial bones; Fig. 2C), accumulation of cerebrospinal fluid, attenuated cerebral parenchyma (Figs. 2D and G) and severe dilatation of the lateral ventricles (Fig. 2G). Intracranial hemorrhage was observed in $4(33 \%)$ out of $12 C c d c 85 c \mathrm{KO}$ rats, which were dead or moribund (Figs. $2 \mathrm{E}$ and F). In contrast, WT and hetero rats did not show any clinical symptoms or pathological abnormality.

Histopathologically, brains of $C c d c 85 c \mathrm{KO}$ rats at $4 \mathrm{~W}$ exhibited dilated lateral ventricles (Fig. 3A) lacking most of the ependymal cells (Fig. 3C), attenuated cerebral parenchyma (Fig. 3A) and subcortical heterotopia (Figs. $4 \mathrm{~A}$ and $\mathrm{B}$ ). In $C c d c 85 c \mathrm{KO}$ rats, hemorrhage was observed in the meninges (Fig. 3B). Dilatation of the lateral ventricles was marked, while the third and fourth ventricles and aqueduct were not affected. Neither causative stenosis nor obstruction in the ventricular system was detected. Ependymal cells were not present at the dorsal or lateral position of the lateral ventricles. No abnormality was observed in the choroid plexus. The subcortical heterotopia of $C c d c 85 c \mathrm{KO}$ rats was broadly distributed and located at the dorsal position of the lateral ventricles (Fig. 4A). These histopathological features of $C c d c 85 c \mathrm{KO}$ rats are similar to those of hhy mice.

\section{Discussion}

Ccdc85c KO rats as a new model of hydrocephalus and subcortical heterotopia

In this study, we have successfully established $C c d c 85 c$ KO rats that had a 355-bp deletion in $C c d c 85 c$ accompanied by non-obstructive hydrocephalus, subcortical heterotopia without ependymal cells in the dorsal or lateral position of the ventricles, and occasional intracranial hemorrhage. These pathological characteristics are very similar to those of hhy mice [11]. HTX rats are known as a congenital hydrocephalus model [10], and hydrocephalus in HTX rats is caused by abnormal development of the subcommissural organ followed by closure of the cerebral aqueduct; however, the causative gene is unknown [8, 9, 22]. As a spontaneous cortical heterotopia model, telencephalic internal structural heterotopia (tish) rats have been reported [12]. Tish rats show subcortical band heterotopia, which is associated with seizures. Subcortical band heterotopia in tish rats is caused by dysregulation of the positioning, number and cell-cycle kinetics of neural progenitor cells [4]. In contrast to these rat models, $C c d c 85 c$ KO rats showed various pathological phenotypes simultaneously. Therefore $C c d c 85 c \mathrm{KO}$ rats may serve as a novel, unique model of both congenital hydrocephalus and subcortical heterotopia.

These pathological characteristics of $C c d c 85 c \mathrm{KO}$ rats are very similar to those of hhy mice. In this study, all $12 C c d c 85 c \mathrm{KO}$ rats showed hydrocephalus and four of them also had intracranial hemorrhage. The frequency of intracranial hemorrhage (33\%) was lower than in mice (87\%) [11].The fact that the frequency of intracranial hemorrhage was lower than that of hydrocephalus in both species indicates that the intracranial hemorrhage followed the hydrocephalus. It is known that intracerebral hemorrhage causes secondary hydrocephalus in humans and subarachnoid hemorrhage model rats; however, hydrocephalus accompanied by hemorrhage has not previously been reported except in hhy mice [3, 5, $7,11,13,16]$. The intracranial hemorrhage in $C c d c 85 c$ $\mathrm{KO}$ animals is presumed to be secondary, but elucidating the pathogenesis of the hemorrhage in $C c d c 85 \mathrm{c}$ mutants may contribute to novel findings about intracranial hemorrhage.

\section{Pathogenesis of the lesions in Ccdc85c KO rats}

This study leaves unclear the pathogenesis of the nonobstructive hydrocephalus in $C c d c 85 c$ KO rats. Because of the comparatively low frequency of intracranial hemorrhage (33\%), we considered that hydrocephalus in $C c d c 85 c \mathrm{KO}$ rats was not secondary to the intracranial 

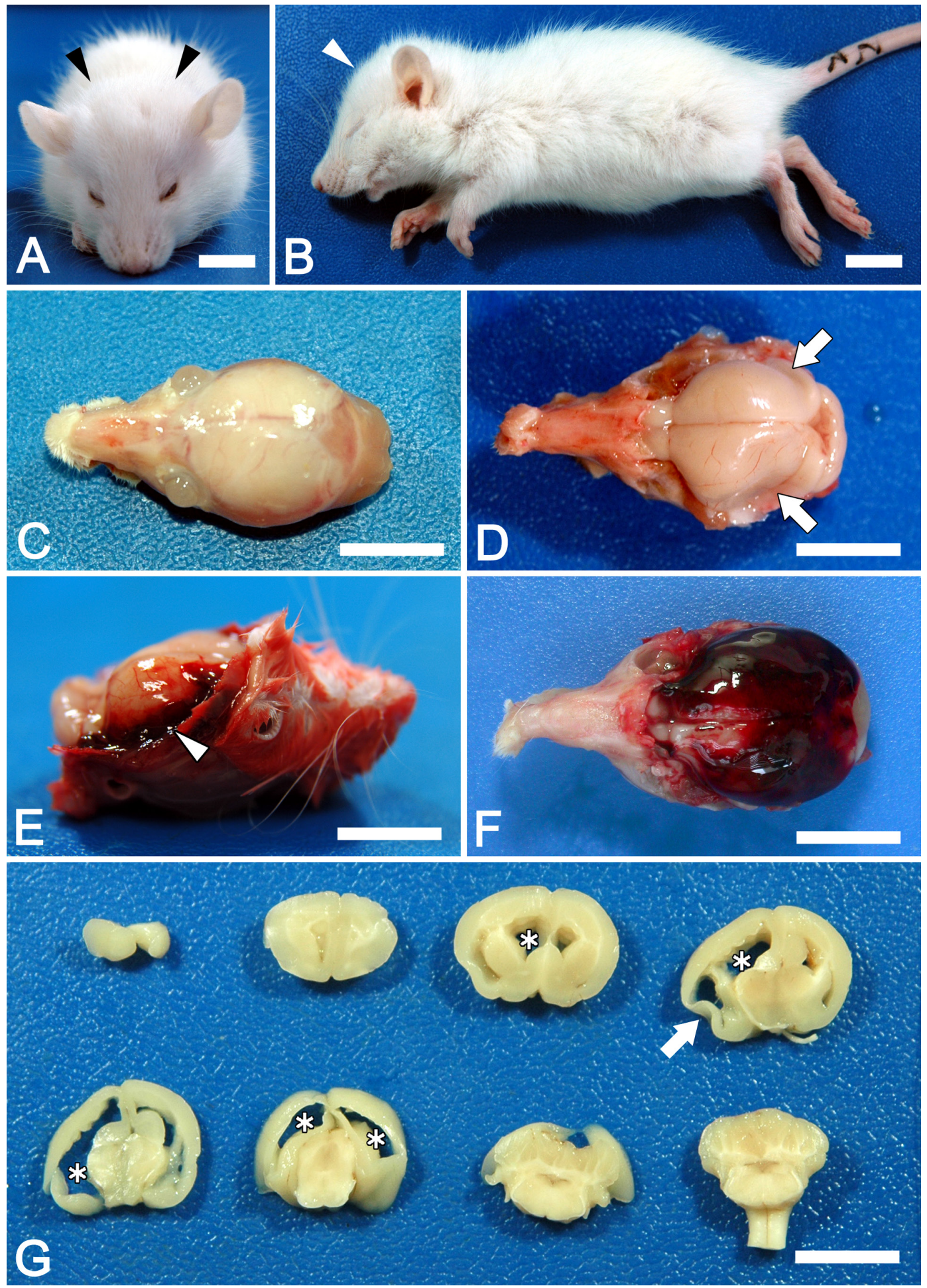

Fig. 2. Macroscopic phenotype of $C c d c 85 c \mathrm{KO}$ rats at four weeks of age (4W). $C c d c 85 c \mathrm{KO}$ rats showed enlarged heads (A and B, arrowheads). Hydrocephalus causes skull thinning (C) and attenuated cerebral parenchyma (D, arrowheads). Intracranial hemorrhage is observed in some $C c d c 85 c \mathrm{KO}$ rats (E, arrowhead: hemorrhage at temporal region, F: severe hemorrhagic case; blood clot covered the whole cerebrum). Dilated lateral ventricles (asterisks) and attenuated cerebral parenchyma (arrow) are observed in coronally sliced brain (G). Scale bars, $1 \mathrm{~cm}$.

hemorrhage. There were no ependymal cells in the dorsal or lateral position of the ventricles in the $C c d c 85 c$ $\mathrm{KO}$ rats. In hhy mice, this pathological change is conspicuous and is considered to be caused by ependymal agenesis [16]. It is known that ependymal cell abnormality causes hydrocephalus by inhibiting ependymal flow $[6,26]$. Taken together, these findings support the hypothesis that hydrocephalus in $C c d c 85 c \mathrm{KO}$ rats is di- 


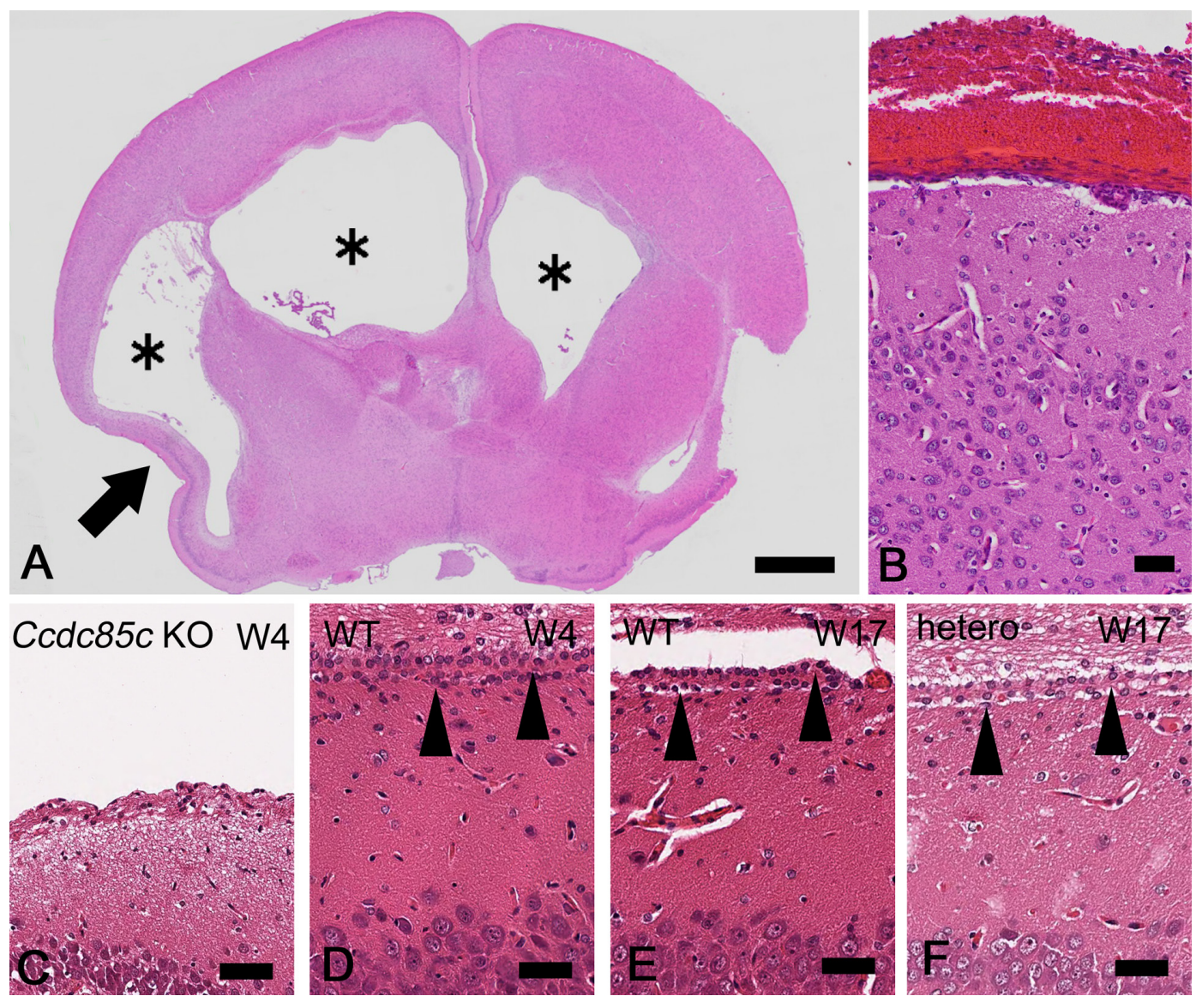

Fig. 3. Histopathological analysis of hydrocephalus in $C c d c 85 c \mathrm{KO}$ rats. HE stained sections of cerebrum in $C c d c 85 c$ $\mathrm{KO}$ rats at four weeks of age $(4 \mathrm{~W})(\mathrm{A}-\mathrm{C})$ and unaffected rats at $4 \mathrm{~W}[\mathrm{D}$ : wild type $(\mathrm{WT})]$ or at $17 \mathrm{~W}(\mathrm{E}: \mathrm{WT}$, F: hetero). Lateral ventricles are dilated in $C c d c 85 c \mathrm{KO}$ rats (A, asterisks). Atrophied cerebral parenchyma is also observed (A, arrow). Hemorrhage is mainly located at meninges (B). Lateral ventricles are lined by ependymal cells in WT rat and hetero rat (D-F, arrowheads). There are no ependymal cells at the lateral ventricles in $C c d c 85 c$ KO rats (C). Scale bar of A, $1 \mathrm{~mm}$, scale bar of B, $50 \mu \mathrm{m}$, scale bar of C-F, $25 \mu \mathrm{m}$.

rectly related to the agenesis of ependymal cells. However, to demonstrate this, we should investigate whether or not the lack of ependymal cells in $C c d c 85 c \mathrm{KO}$ rats is a primary change.

$C c d c 85 c$ KO rats showed subcortical heterotopia formation and ependymal cell agenesis. Subcortical heterotopia is characterized by the presence of neurons that do not complete their migration [21]. Cerebral cortex is a tissue in which orderly layers of laminated neurons are generated during development. This neuronal lamination in the cerebral cortex is known to be disrupted by abnormalities of various factors such as cell adhesion molecules, cell polarity molecules and signaling molecules $[14,17,23,28,29]$. Ependymal precursors are derived from radial glial cells that become neural stem cells on the ventricular surface [24]. In hhy mice, the agenesis of ependymal cells occurs in the paramedio-dorsal position of the subcortical areas, where subcortical heterotopia develops both in the $C c d c 85 c \mathrm{KO}$ rats of the present study and in hhy mice. Recently, the proper development of medial wall ependymal cilia was shown to be important for normal brain development, and dysfunction of ependymal cells was suggested to cause an aqueductal disturbance, leading to hydrocephalus in $C c d c 39$ mutant mice [1]. Therefore our present results indicate that CCDC 85C in rats as well as in hhy mice plays an important role in neurogenesis in the cerebrum of rats, and the lack of it causes abnormal neuronal migration.

In the previous study in rats [25], CCDC85C expression was especially strong in the small intestine, cerebrum, cerebellum and eye. Morphological maturation occurs in the small intestine by P42, the brain by P21, and the retina by P25 [18, 19, 27]. In the present study, $C c d c 85 c \mathrm{KO}$ rats had abnormalities in the cerebrum but no malformations in the small intestine or cerebellum. By heterozygous mating, the observed value (16.4\%) was lower than the expected frequency of homozygous pups $(25 \%)$. Since neonatal rats in poor condition were killed by the mother, the actual incidence is expected to be close to $25 \%$. Therefore, it is likely that the defi- 


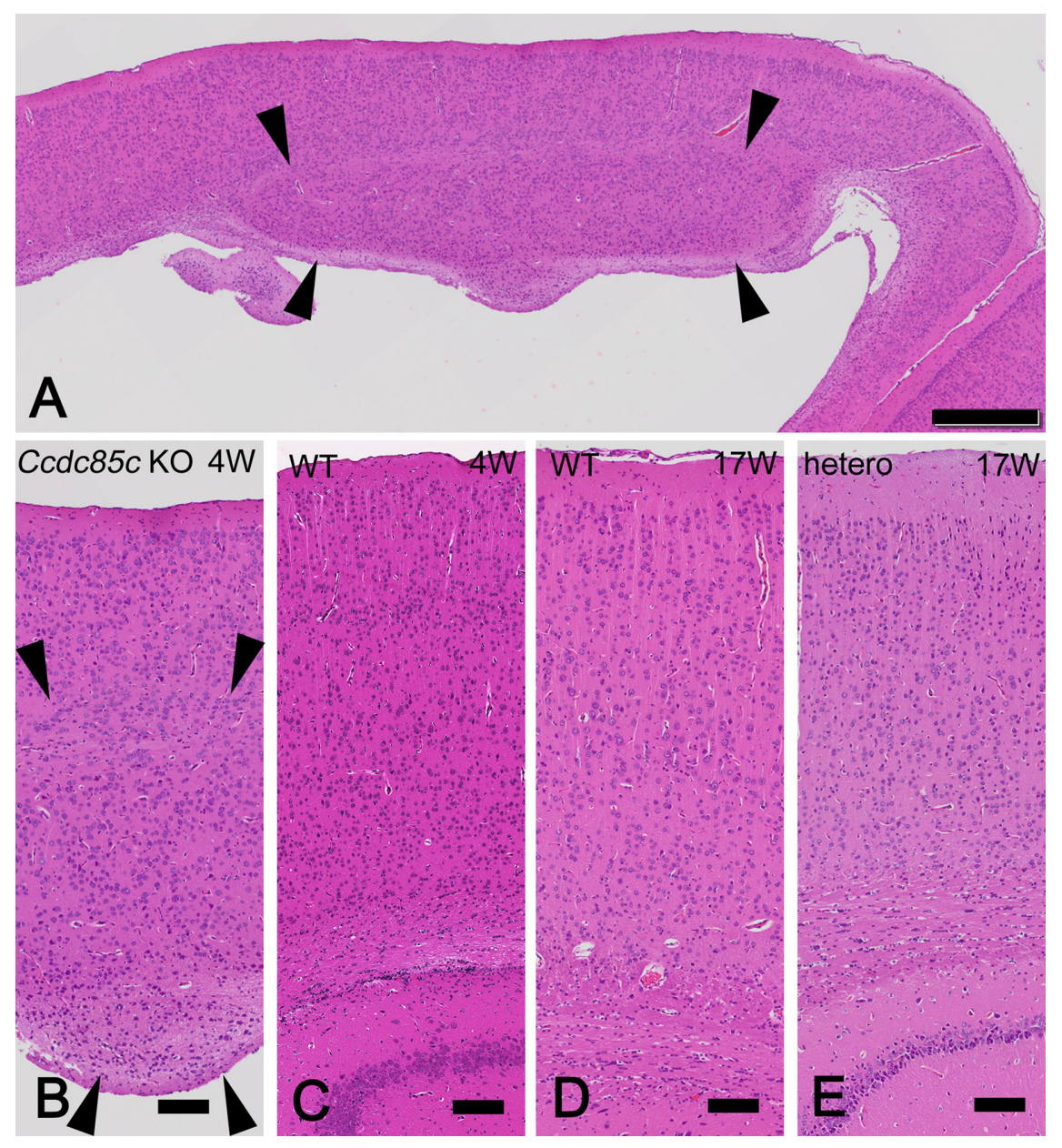

Fig. 4. Histopathology of subcortical heterotopia in $C c d c 85 c$ KO rats. HE stained sections of cerebrum in $C c d c 85 c \mathrm{KO}$ rats at four weeks of age (4W) (A and B) and unaffected rats at $4 \mathrm{~W}$ [C: wild type (WT)] or at 17W (D: WT, E: hetero). Subcortical heterotopia is broadly formed at the dorsal surface of lateral ventricles in $C c d c 85 c \mathrm{KO}$ rats (A and B, arrowheads). No lesion is observed at the cerebral parenchyma in WT and hetero rats (C-E). Scale bar of A, $500 \mu \mathrm{m}$, scale bars of B-E, $100 \mu \mathrm{m}$.

ciency of CCDC85C protein was not lethal to the fetus. These results imply that the function of CCDC $85 \mathrm{C}$ in organ maturation is more important in the cerebrum than in other organs.

\section{Acknowledgments}

$\mathrm{Ccdc} 85 \mathrm{c} \mathrm{KO}\left(\mathrm{F} 344-\mathrm{Ccdc} 85 c^{\text {em1Kyo }}\right)$ rats were deposited at National BioResource Project (NBRP)-Rat (NBRP Rat No. 0824). This work was supported by Grant-in-Aid for Scientific Research from Japan Society for Promotion of Science (JSPS; no. 15H04595) and Kenyuukai (The Veterinary Practitioners Association of Osaka Prefecture University). We thank Dr. Gerald E. Smyth for his English-language editing of the manuscript.

\section{References}

1. Abdelhamed, Z., Vuong, S.M., Hill, L., Shula, C., Timms, A., Beier, D., Campbell, K., Mangano, F.T., Stottmann, R.W. and Goto, J. 2018. A mutation in $C c d c 39$ causes neonatal hydrocephalus with abnormal motile cilia development in mice. Development 145: dev154500. [Medline] [CrossRef]

2. Amos-Landgraf, J.M., Kwong, L.N., Kendziorski, C.M., Reichelderfer, M., Torrealba, J., Weichert, J., Haag, J.D., Chen, K.S., Waller, J.L., Gould, M.N. and Dove, W.F. 2007. A target-selected Apc-mutant rat kindred enhances the modeling of familial human colon cancer. Proc. Natl. Acad. Sci. USA 104: 4036-4041. [Medline] [CrossRef]

3. Burstein, J., Papile, L.A. and Burstein, R. 1979. Intraventricular hemorrhage and hydrocephalus in premature newborns: a prospective study with CT. AJR Am. J. Roentgenol. 132: 631-635. [Medline] [CrossRef]

4. Fitzgerald, M.P., Covio, M. and Lee, K.S. 2011. Disturbances in the positioning, proliferation and apoptosis of neural progenitors contribute to subcortical band heterotopia formation. Neuroscience 176: 455-471. [Medline] [CrossRef]

5. Hasan, D., Vermeulen, M., Wijdicks, E.F.M., Hijdra, A. and van Gijn, J. 1989. Management problems in acute hydro- 
cephalus after subarachnoid hemorrhage. Stroke 20: 747-753. [Medline] [CrossRef]

6. Ibañez-Tallon, I., Pagenstecher, A., Fliegauf, M., Olbrich, H., Kispert, A., Ketelsen, U.P., North, A., Heintz, N. and Omran, H. 2004. Dysfunction of axonemal dynein heavy chain Mdnah5 inhibits ependymal flow and reveals a novel mechanism for hydrocephalus formation. Hum. Mol. Genet. 13: 21332141. [Medline] [CrossRef]

7. Jing, C., Zhang, H., Shishido, H., Keep, R.F. and Hua, Y. 2018. Association of brain CD163 expression and brain injury/hydrocephalus development in a rat model of subarachnoid hemorrhage. Front. Neurosci. 12: 313. [Medline] [CrossRef]

8. Jones, H.C. and Bucknall, R.M. 1988. Inherited prenatal hydrocephalus in the H-Tx rat: a morphological study. Neuropathol. Appl. Neurobiol. 14: 263-274. [Medline] [CrossRef]

9. Jones, H.C., Carter, B.J., Depelteau, J.S., Roman, M. and Morel, L. 2001. Chromosomal linkage associated with disease severity in the hydrocephalic H-Tx rat. Behav. Genet. 31: 101-111. [Medline] [CrossRef]

10. Kohn, D.F., Chinookoswong, N. and Chou, S.M. 1981. A new model of congenital hydrocephalus in the rat. Acta Neuropathol. 54: 211-218. [Medline] [CrossRef]

11. Kuwamura, M., Kinoshita, A., Okumoto, M., Yamate, J. and Mori, N. 2004. Hemorrhagic hydrocephalus (hhy): a novel mutation on mouse chromosome 12. Brain Res. Dev. Brain Res. 152: 69-72. [Medline] [CrossRef]

12. Lee, K.S., Schottler, F., Collins, J.L., Lanzino, G., Couture, D., Rao, A., Hiramatsu, K., Goto, Y., Hong, S.C., Caner, H., Yamamoto, H., Chen, Z.F., Bertram, E., Berr, S., Omary, R., Scrable, H., Jackson, T., Goble, J. and Eisenman, L. 1997. A genetic animal model of human neocortical heterotopia associated with seizures. J. Neurosci. 17: 6236-6242. [Medline] [CrossRef]

13. Lodhia, K.R., Shakui, P. and Keep, R.F. 2006. Hydrocephalus in a rat model of intraventricular hemorrhage. Acta Neurochir. Suppl. (Wien) 96: 207-211. [Medline] [CrossRef]

14. Masai, I., Lele, Z., Yamaguchi, M., Komori, A., Nakata, A., Nishiwaki, Y., Wada, H., Tanaka, H., Nojima, Y., Hammerschmidt, M., Wilson, S.W. and Okamoto, H. 2003. N-cadherin mediates retinal lamination, maintenance of forebrain compartments and patterning of retinal neurites. Development 130: 2479-2494. [Medline] [CrossRef]

15. Mashimo, T., Takizawa, A., Kobayashi, J., Kunihiro, Y., Yoshimi, K., Ishida, S., Tanabe, K., Yanagi, A., Tachibana, A., Hirose, J., Yomoda, J., Morimoto, S., Kuramoto, T., Voigt, B., Watanabe, T., Hiai, H., Tateno, C., Komatsu, K. and Serikawa, T. 2012. Generation and characterization of severe combined immunodeficiency rats. Cell Rep. 2: 685-694. [Medline] [CrossRef]

16. Mori, N., Kuwamura, M., Tanaka, N., Hirano, R., Nabe, M., Ibuki, M. and Yamate, J. 2012. $C c d c 85 c$ encoding a protein at apical junctions of radial glia is disrupted in hemorrhagic hydrocephalus (hhy) mice. Am. J. Pathol. 180: 314-327. [Medline] [CrossRef]

17. Ouchi, Y., Baba, Y., Koso, H., Taketo, M.M., Iwamoto, T.,
Aburatani, H. and Watanabe, S. 2011. $\beta$-Catenin signaling regulates the timing of cell differentiation in mouse retinal progenitor cells. Mol. Cell. Neurosci. 46: 770-780. [Medline] [CrossRef]

18. Picut, C.A. and Coleman, G.D. 2016. Gastrointestinal Tract. pp. 127-171. In: Atlas of histology of the Juvenile rat. (Parker, G.A., and Picut, C.A. eds.), Academic Press, London.

19. Picut, C.A., Brown, D.L. and Remick, A.K. 2016. Nervous System. pp. 45-87. In: Atlas of histology of the Juvenile rat. (Parker, G.A., and Picut, C.A. eds.), Academic Press, London.

20. Sakuma, T., Ochiai, H., Kaneko, T., Mashimo, T., Tokumasu, D., Sakane, Y., Suzuki, K., Miyamoto, T., Sakamoto, N., Matsuura, S. and Yamamoto, T. 2013. Repeating pattern of nonRVD variations in DNA-binding modules enhances TALEN activity. Sci. Rep. 3: 3379. [Medline] [CrossRef]

21. Sisodiya, S.M. 2004. Malformations of cortical development: burdens and insights from important causes of human epilepsy. Lancet Neurol. 3: 29-38. [Medline] [CrossRef]

22. Somera, K.C. and Jones, H.C. 2004. Reduced subcommissural organ glycoprotein immunoreactivity precedes aqueduct closure and ventricular dilatation in H-Tx rat hydrocephalus. Cell Tissue Res. 315: 361-373. [Medline] [CrossRef]

23. Sottocornola, R., Royer, C., Vives, V., Tordella, L., Zhong, S., Wang, Y., Ratnayaka, I., Shipman, M., Cheung, A., GastonMassuet, C., Ferretti, P., Molnár, Z. and Lu, X. 2010. ASPP2 binds Par-3 and controls the polarity and proliferation of neural progenitors during CNS development. Dev. Cell 19: 126137. [Medline] [CrossRef]

24. Spassky, N., Merkle, F.T., Flames, N., Tramontin, A.D., García-Verdugo, J.M. and Alvarez-Buylla, A. 2005. Adult ependymal cells are postmitotic and are derived from radial glial cells during embryogenesis. J. Neurosci. 25: 10-18. [Medline] [CrossRef]

25. Tanaka, N., Izawa, T., Takenaka, S., Yamate, J. and Kuwamura, M. 2015. Ccdc85C, a causative protein for hydrocephalus and subcortical heterotopia, is expressed in the systemic epithelia with proliferative activity in rats. Histol. Histopathol. 30: 823-832. [Medline]

26. Tissir, F., Qu, Y., Montcouquiol, M., Zhou, L., Komatsu, K., Shi, D., Fujimori, T., Labeau, J., Tyteca, D., Courtoy, P., Poumay, Y., Uemura, T. and Goffinet, A.M. 2010. Lack of cadherins Celsr2 and Celsr3 impairs ependymal ciliogenesis, leading to fatal hydrocephalus. Nat. Neurosci. 13: 700-707. [Medline] [CrossRef]

27. Walling, B.E. and Marit, G.B. 2016. The Eye and Harderian Gland. pp. 373-394. In: Atlas of histology of the Juvenile rat. (Parker, G.A., and Picut, C.A. eds.), Academic Press, London.

28. Wei, X., Cheng, Y., Luo, Y., Shi, X., Nelson, S. and Hyde, D.R. 2004. The zebrafish Pard3 ortholog is required for separation of the eye fields and retinal lamination. Dev. Biol. 269: 286-301. [Medline] [CrossRef]

29. Zheng, M.H., Shi, M., Pei, Z., Gao, F., Han, H. and Ding, Y.Q. 2009. The transcription factor RBP-J is essential for retinal cell differentiation and lamination. Mol. Brain 2: 38. [Medline] [CrossRef] 